\title{
ARTIGO DE ATUALIZAÇÃO Influência da estrutura de governança
UPDATE ARTILLE no desenvolvimento das competências organizacionais: estudo nos serviços de saúde
}

\author{
Influence of governance structure on organizational \\ competency development: health services study \\ Djair Picchiai', Roseli Soligo² \\ DOI: $10.21115 / J B E S . v 10 . n 2 . p 203-212$
}

\section{Palavras-chave:}

custos de transação, estruturas de governança, competências organizacionais, serviços de saúde

\section{Keywords:}

transaction costs, governance structures, organizational skills, health services

\begin{abstract}
RESUMO
O objetivo deste artigo foi identificar a influência da estrutura de governança no desenvolvimento das competências organizacionais, na perspectiva da Economia dos Custos de Transação (ECT). Analisaram-se duas empresas de uma corporação da área da saúde atuantes em Campinas e região. O portfólio de ambas são exames de diagnóstico por imagem (ressonância magnética [RM], tomografia, ultrassom e mamografia). O presente estudo caracterizou-se como um estudo de caso exploratório (Yin, 2001). Devido a um forte crescimento da demanda de exames de RM na matriz, foi necessária a contratação de um fornecedor especializado nessa modalidade, para quem foi transferida apenas e tão somente a atividade de laudos de baixa complexidade, e assim a estrutura de governança da matriz passou a ser híbrida. Os resultados do estudo apontaram que as estruturas de governança não somente influenciaram no desenvolvimento de novas, como interagiram para o fortalecimento e a eliminação de algumas competências organizacionais vigentes.
\end{abstract}

Recebido em: 04/05/2018. Aprovado para publicação em: 06/08/2018

1. Professor doutor em Administração de Empresas pela Escola de Administração de Empresas de São Paulo da Fundação Getulio Vargas (Eaesp-FGV) e Centro Universitário Campo Limpo Paulista (UNIFACCAMP), Campo Limpo Paulista, SP.

2. Mestranda em Administração de Empresas pela Faculdade Campo Limpo Paulista (Faccamp).

Local onde o estudo foi realizado: Escola de Administração de Empresas de São Paulo da Fundação Getulio Vargas (Eaesp-FGV), São Paulo, SP.

Conflitos de interesse: Não há conflitos de interesse a serem declarados

Autor correspondente: Djair Picchiai. Eaesp-FGV. Rua Itapeva, 474, Bela Vista, São Paulo, SP. CEP: 01332-000. E-mail: djair.picchiai@fgv.br 


\section{Introdução}

Diversos são os fatores que têm levado as empresas a optarem pela terceirização. Entre eles, destacam-se: especialização do prestador de serviço, aquisição e atualização de novas tecnologias, redução de custos, ausência de recursos internos, possibilidade de melhoria dos serviços prestados e aumento de produtividade.

Com a consolidação do novo modelo de trabalho construído com base na telerradiologia (sistemas de telecomunicações usados para transferir imagens radiológicas de um local para outro), normatizado no Brasil desde janeiro de 2009, novas oportunidades empresariais foram criadas. Essa tecnologia possibilitou que muitas empresas fossem criadas para oferecer serviço de laudo a distância.

Quando a demanda de exames excedeu a capacidade de sua equipe interna, essa nova modalidade de trabalho passou a ser uma alternativa para que as clínicas de diagnóstico por imagem ajustassem os picos de alta demanda contratando empresas especializadas na execução de laudo a distância, principalmente de exames de ressonância magnética (RM). O contratante tem como garantia a constância dos serviços prestados, com grandes expectativas de redução de custos, otimização na utilização dos recursos humanos e tecnológicos e aumento da produtividade.

A mão de obra médica para essa prestação de serviço é especializada. Há alguns anos, médicos radiologistas eram uma mão de obra muito escassa no mercado, o que dificultou a contratação e a retenção desses especialistas. A pressão por ganhos maiores cresceu exponencialmente e muitas clínicas foram obrigadas a rever suas estratégias.

É recomendável que principalmente clínicas de pequeno porte atuem com inteligência visando a interesses empresariais, mantendo-se presente em novos mercados que surgirem. Não cabe contar apenas com eficiência e competitividade perenes, pois a inovação incessante pode ameaçar a sobrevivência.

Neste contexto, o presente estudo tem como primeira intenção fortalecer o conhecimento sobre as relações entre abordagens da economia das organizações e capacitações organizacionais.

Procurou-se averiguar se e como a escolha da estrutura de governança pôde influenciar no desenvolvimento das competências organizacionais, considerando as dimensões dos custos de transação. O conjunto de atividades desempenhadas na corporação pode ser representado pela Figura 1.

A análise do fenômeno se dará em torno da terceirização da atividade de execução de laudos exclusivamente de RM.

Os exames de RM serão reclassificados por nível de complexidade (C1: baixa; C2: média; C3: alta) das partes do corpo humano, conforme mostra a Tabela 1.

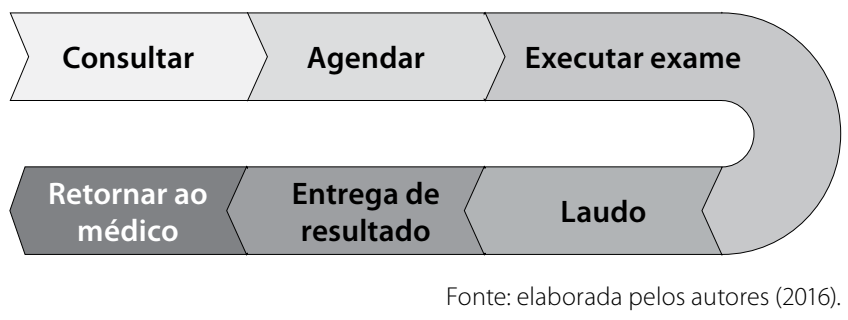

Figura 1. Representação do fluxo de valor comum para a corporação.

\section{Fundamentação teórica}

O referencial teórico que norteou essa pesquisa foi a Economia dos Custos de Transação (ECT), que se iniciou com Ronald Coase (1937), em seu clássico artigo "The nature of the firm", ressaltando a importância da estrutura institucional da produção (firma) em detrimento da teoria econômica tradicional que estuda os modos de coordenação via preço (mercado). Segundo Fiani et al. (2002), antes de Coase (1937), supunha-se que os custos associados às transações eram negligenciáveis de tal forma que o que realmente importava eram os custos de produção.

Coase foi precursor da Nova Economia Institucional (NEI), que aborda a firma como um conjunto de variáveis influenciadas pelo ambiente externo e expõe-na a diversos cenários econômicos e a uma diversidade de competidores.

Em suma, os esforços de teorização desempenhados por Coase abririam caminho para estudos sistemáticos sobre as formas de organização das firmas e mercados segundo a perspectiva dos custos, vinculada à problemática da coordenação das atividades econômicas e ao papel das instituições (Pondé, 1994).

Para Williamson (1993), existem custos na utilização tanto do mecanismo de preço (estrutura de mercado) quanto na condução de contratos internos (estrutura das firmas), os quais mudam conforme as características da transação e do ambiente competitivo.

A ECT enfatiza o sistema produtivo essencialmente como um tecido de arranjos contratuais, entendendo, portanto, o problema da organização econômica como um problema contratual (Williamson, 1985).

Tabela 1. Identificação dos procedimentos de RM por nível de complexidade

\begin{tabular}{ll}
\hline $\begin{array}{l}\text { Nível de } \\
\text { complexidade }\end{array}$ & Procedimentos de RM \\
\hline C1 & Articulações, coluna, joelho e seios da face \\
\hline C2 & Abdome, crânio e pescoço, tórax \\
\hline C3 & $\begin{array}{l}\text { Cardíaca, espectrorressonância, } \\
\text { angiorressonância }\end{array}$ \\
\hline
\end{tabular}

Fonte: elaborada pelos autores (2016). 
Assim, em termos gerais, a ECT propõe uma interpretação sobre o funcionamento das firmas e mercados, tendo a transação como unidade básica de análise. Essa última é definida como o evento em que um bem ou serviço é transferido por meio de uma interface tecnologicamente separável, sendo passível de estudo enquanto relação contratual, uma vez que envolve interações e compromissos intertemporais entre os agentes (Williamson, 1985).

Outro referencial teórico é o de competências organizacionais apoiado nos conceitos desenvolvidos por Prahalad e Hamel (1995), Ruas et al. (2005) e King (2002).

\section{Economia do custo de transação}

A ECT esclarece que as empresas possuem, além de custos de produção, custos de transação, o que significa que para o sistema econômico funcionar, é importante tanto os contratos via mercado como os coordenados pela empresa.

Fiani et al. (2002), baseando-se em Williamson e Coase, define custos de transação como aqueles gerados para organizar o funcionamento do sistema econômico, dada a divisão do trabalho - divisão das tarefas produtivas -, seja no interior de uma mesma unidade produtiva (dentro da própria empresa), seja entre diferentes unidades produtivas (entre empresas), ou seja, os custos de transação são aqueles resultantes quando um ativo, um recurso produtivo, atravessa uma interface tecnológica.

As transações apresentam diferenças nas suas características que afetam os custos de transação, fazendo com que em determinadas transações estes sejam mais importantes do que em outras. Nos casos em que os custos são elevados, o mercado não se mostra uma opção viável para a organização dos processos de produção, levando a empresa a recorrer a novas formas de organizar os processos produtivos (Fiani et al., 2002).

Os custos de transação surgem principalmente em razão das dificuldades com que as transações lidam devido a fatores comportamentais dos indivíduos: a racionalidade limitada e o oportunismo, bem como os atributos e as características das transações (especificidade de ativos, frequência e incerteza), sendo possível escolher a estrutura de governança que proporcione o menor custo de transação (Williamson, 1979).

Segundo Williamson (1991), os custos de transação podem ser entendidos em três pontos fundamentais: I) as transações e seus respectivos custos definem os diferentes modos de estrutura institucional na organização das atividades econômicas; II) a tecnologia, mesmo sendo uma importante ferramenta de organização das atividades econômicas nas empresas, não é determinante desta; III) as falhas de mercado são centrais à análise da estrutura dos custos de transação, conferindo importância às formas institucionais.
De acordo com Williamson (1985), são três as estruturas básicas de governança de transações: mercado, híbrida e hierárquica.

\section{Atributos das transações}

Williamson (1985; 1991) define os seguintes atributos para as transações: I) frequência da transação: indica a frequência com que cada tipo de transação ocorre em um dado período; II) incerteza da transação: refere-se à possibilidade de ocorrência de situações não previstas que podem afetar a transação. Podem ser situações imprevistas ligadas ao risco de não fornecimento e ao consequente desabastecimento, à qualidade do ativo, à majoração inesperada de preços no mercado, de custos de logística, à entrada de produtos substitutos, de exigências legais etc.; III) especificidade dos ativos: situações muito particulares sobre o produto ou serviço; a continuidade da transação a qual ele é específico depende de sua utilização.

Williamson (1985) seleciona quatro fatores que podem determinar o surgimento de ativos específicos: I) especificidades de natureza locacional relacionada à exigência de proximidade geográfica entre as partes que transacionam, sob pena de se perderem os investimentos realizados em caso de troca de demandante ou ofertante; II) especificidades de ativos dedicados relacionadas à expansão de capacidade produtiva são direcionadas e dimensionadas unicamente para atender à demanda de um conjunto de transações, implicando uma inevitável ociosidade no caso de interrupção da relação; III) especificidades de ativos físicos relacionadas à aquisição de equipamentos dedicados a ofertar ou consumir os bens ou serviços transacionados, ou seja, unidades de capital fixo especializadas e que atendem a requerimentos particulares da outra parte envolvida na relação; IV) especificidades do ativo humano relacionadas a investimentos realizados na capacitação humana por meio de cursos formais ou aprender fazendo, que fazem com que demandantes e ofertantes de determinados produtos acabem se servindo mutuamente com mais eficiência do que poderiam fazer com novos parceiros.

Neste estudo, as especificidades consideradas foram a dos ativos humanos, pois os laudos emitidos pelos médicos radiologistas pressupõem certo grau de conhecimento específico.

Para compreender a ECT, Williamson (1993) definiu pressupostos comportamentais: I) racionalidade limitada: refere-se ao grau de limitações e conhecimentos dos agentes envolvidos na transação para tomada de decisões; II) oportunismo: refere-se a ações que resultam de assimetrias de informações associadas a esforços premeditados dos agentes da transação para enganar, deturpar, disfarçar, omitir e até manipular informações de interesse da outra parte. Parte-se de 
um princípio de jogo não cooperativo, pois na impossibilidade de acesso de um agente sobre a realidade do outro, possibilita que uma parte desfrute de algum benefício exclusivo.

A presença do oportunismo e da racionalidade limitada nos indivíduos leva os agentes da transação a se resguardarem por meio de instituições chamadas de contratos.

Os estudos de Williamson (1985) destacam as seguintes estruturas de governança para as transações e suas características (Tabela 2).

\section{Dimensões e competências nas organizações}

Muitas empresas têm grandes dificuldades para identificar e avaliar as competências que possuem. A gerência de nível intermediário pode desempenhar um papel importante tanto para o desenvolvimento como para a manutenção das competências organizacionais. As competências são a combinação de conhecimentos e habilidades; representam tanto a base dos conhecimentos tácitos quanto o conjunto de habilidades necessários à realização de ações produtivas. Assumem caráter estratégico à medida que dispõem dos seguintes atributos: o caráter tácito, a robustez, a fixação e o consenso de gerências (King, 2002).

Prahalad e Hamel (1995) definem competências essenciais (core competence) como "um conjunto de habilidades e tecnologias que permitem a uma empresa oferecer um determinado benefício aos clientes". Competências essenciais são habilidades ou capacidades, não são produtos ou serviços. Para esses autores, uma competência essencial da organização deve: I) ser visível aos olhos do cliente e não às nuanças técnicas, aportar uma contribuição importante e não apenas implícita ao benefício; II) mostrar diferenciação da empresa com seus concorrentes e ser difícil de copiar ou imitar; III) possibilitar a expansão, ou seja, viabilizar o acesso a diferentes mercados.

Com base nesses conceitos de Prahalad e Hamel (1995), Ruas et al. (2005) procuram adaptá-los à realidade das pequenas e médias empresas e propõem os seguintes conceitos: l) competências organizacionais: são competências coletivas que se distinguem sob a forma de processos e/ou atendimento e abrigam conhecimentos tácitos e explícitos, sistemas e procedimentos de trabalho, entre outros elementos intangíveis, como princípios, valores e cultura dominantes na organização; II) competências organizacionais básicas: são as competências coletivas desmembradas em toda organização que contribuem para a sobrevivência da organização, mas não para sua diferenciação; III) competências organizacionais seletivas: são competências coletivas que geram diferenciação.

Ao realizar escolhas, a empresa aumenta as chances de definir uma boa estratégia. O planejamento deve direcionar a organização à adoção de estratégias competitivas. Segundo Fleury e Fleury (2010), são três: I) excelência operacional: caracteriza empresas que buscam competir com base no custo, procurando oferecer a seus clientes um produto médio com o melhor preço e bom atendimento; II) inovação no produto: caracteriza empresas que procuram oferecer a seus clientes produtos de ponta, inovando sempre; III) orientada a servi-

Tabela 2. Estruturas de governança e suas características

\begin{tabular}{|c|c|c|c|c|c|}
\hline Atributos & & & Comportamento & & \begin{tabular}{|l} 
Estrutura de \\
governança
\end{tabular} \\
\hline $\begin{array}{l}\text { Especificidade } \\
\text { do ativo }\end{array}$ & Incerteza & Frequência & Racionalidade limitada & Oportunismo & \\
\hline Baixa & Baixa & Baixa & $\begin{array}{l}\text { Sem especificidades } \\
\text { de ativos, não } \\
\text { há assimetria de } \\
\text { conhecimento, o que } \\
\text { reduz o poder de } \\
\text { decisão das partes }\end{array}$ & $\begin{array}{l}\text { Tendência de não } \\
\text { existir pela ausência } \\
\text { de especificidades } \\
\text { dos ativos }\end{array}$ & Mercado \\
\hline Alta & Alta & Alta & $\begin{array}{l}\text { Decisão de produzir } \\
\text { internamente; } \\
\text { neutraliza a } \\
\text { assimetria de } \\
\text { informações }\end{array}$ & $\begin{array}{l}\text { Relacionamentos } \\
\text { internos; gerenciar } \\
\text { apenas possíveis } \\
\text { conflitos; não há } \\
\text { espaço para o } \\
\text { oportunismo }\end{array}$ & Hierarquia \\
\hline Média-alta & Média-alta & Média & $\begin{array}{l}\text { Tendência de } \\
\text { assimetria do nível } \\
\text { de conhecimento } \\
\text { e poder de decisão } \\
\text { dos agentes }\end{array}$ & $\begin{array}{l}\text { A assimetria de } \\
\text { informações e o } \\
\text { conhecimento são } \\
\text { precedentes de } \\
\text { comportamentos } \\
\text { oportunistas }\end{array}$ & Híbrida \\
\hline
\end{tabular}

Fonte: elaborada pelos autores (2016). 
ços: caracteriza empresas voltadas a atender o que clientes específicos desejam; especializam-se em satisfazer e até antecipar as necessidades dos clientes em razão de sua proximidade com eles.

A adoção da estratégia de competitividade orientada a serviços sugere a participação dos funcionários, tanto no desenvolvimento como na implantação das estratégias, pois o cliente está presente no ato da prestação do serviço.

As empresas com orientação a serviços devem valorizar a proximidade com o cliente, atender ao que clientes específicos desejam, além de especializar-se em satisfazer e até antecipar as necessidades deles (Fleury \& Fleury, 2010).

Com base nessas referências literárias é que o referido estudo visa analisar as competências desenvolvidas nas empresas estudadas segundo as escolhas das estruturas de governança nas transações de terceirização de laudos de RM.

\section{Metodologia}

Com a finalidade de investigar o fenômeno dentro do seu contexto da vida real, a pesquisa empírica aconteceu por meio de dois estudos de caso (Yin, 2001) em duas empresas especializadas do setor de serviços, segmento de saúde humana, aqui denominadas Alfa e Beta. Ambas desenvolvem diagnósticos médicos por imagem. A empresa Alfa, que é de médio porte (190 funcionários), e a Beta, de pequeno porte (30 funcionários), estão localizadas na região de Campinas. O objeto desse estudo foi a terceirização da execução dos laudos exclusivamente de RM.

A escolha dos casos estudados baseou-se em uma das recomendações propostas por Gil (2010), que é a busca de caso típico em função de informações prévias disponíveis, isto é, na etapa de pré-teste das questões da entrevista com profissionais das empresas, soube-se que estas tinham alguns dos sócios em comum, mas que estes tinham visões e interesses distintos acerca de como configurar a oferta de serviços, no que tange a produzir laudos médicos internamente ou terceirizá-los. Essa informação, aliada à disponibilidade das duas empresas envolvidas em participar do estudo, foi decisiva para a escolha intencional, o que contribuiu para o melhor entendimento do problema de pesquisa (Creswell, 2010).

A título de planejamento do processo de coleta de dados, foi elaborado um protocolo em que se pretendeu elaborar um roteiro de entrevista e pedir autorização para realizar o trabalho nas respectivas empresas, já antecipando em termos gerais as informações de interesse da pesquisa, o tempo de duração das entrevistas, além de assegurar formalmente o compromisso de sigilo sobre os dados e informações coletados.

Os dados foram coletados por meio de duas fontes: entrevistas semiestruturadas e alguns documentos franquea- dos pelos entrevistados. As entrevistas foram realizadas com quatro profissionais, incluindo um diretor clínico (sócio da empresa), um gerente e dois médicos das duas empresas. A escolha desses perfis profissionais foi intencional, considerando que as funções atribuídas a tais cargos pressupõem a fonte principal e imediata para obter informações sobre a estrutura de governança e as competências organizacionais.

A duração das entrevistas foi de aproximadamente 1 hora cada uma, e elas foram gravadas com autorização prévia dos entrevistados e posteriormente transcritas. Dados com interpretações ambíguas ou divergentes dos dados documentais foram retomados e esclarecidos aos entrevistados.

O objetivo do levantamento de dados foi capturar a avaliação dos profissionais envolvidos tanto nas decisões administrativas (diretores e gerentes) e técnicas (médicos) quanto na execução dos serviços essenciais de laudo (responsáveis pela realização dos exames e emissão de laudos para o cliente).

Além disso, para captar as competências desenvolvidas, analisaram-se as informações coletadas em pesquisa de satisfação dos níveis de serviço realizada pela equipe de marketing da corporação no primeiro semestre de 2015. Essa pesquisa foi primeiramente interna com funcionários das duas empresas, na qual, de forma espontânea, foram selecionadas as competências que eles julgavam presentes nas respectivas empresas e que pudessem ser percebidas pelos clientes-pacientes, e que, portanto, as diferenciavam da concorrência. Foram, então, entrevistados quase mil clientes clientes-pacientes - durante os 30 dias úteis de abril de 2015.

Com o mesmo objetivo e no mesmo mês, foi enviado um questionário via e-mail para 30 médicos - clientes médicos solicitantes - com questões pertinentes aos médicos que nos últimos seis meses de 2014 solicitaram um mínimo de 15 exames de RM/mês. Esses questionários foram coletados 15 dias após, em visita feita pelo diretor clínico.

\section{Análises}

\section{Descrição das empresas}

A Alfa é uma empresa de médio porte, com fins lucrativos e de capital fechado, com sede na cidade de Campinas, podendo ser chamada também de matriz. Criada em 1993, passou por uma grande reestruturação administrativa e, em 1997, uma nova estrutura acionária foi formada por dois novos sócios, sendo um radiologista e outro patologista. Assumiram, então, o desafio de incorporar novos métodos ao diagnóstico com o uso de imagem.

Ao final de 2015, a empresa contava com um dimensionamento de 190 funcionários (administrativos, técnicos e de apoio), dos quais 23 médicos.

A empresa adquiriu equipamentos de ultrassom e tomógrafo helicoidal, sendo essas duas modalidades de exames 
responsáveis por $70 \%$ do seu faturamento no período de 1997 a 2001.

Durante 18 anos (1997-2015) nesse ramo de negócio, a matriz construiu sua imagem e foi sendo reconhecida pelos clientes, estando consciente da necessidade permanente de se renovar nos relacionamentos com o mercado. Inicialmente, o foco foi dirigido para a utilização de técnicas modernas e tecnologia de ponta e, na sequência, deu-se a capacitação da equipe.

Os convênios, como um de seus maiores parceiros, direta ou indiretamente, a impulsionaram a tomar decisões em relação a estratégia de expansão das instalações e aquisição e atualização dos equipamentos, para, assim, atender à demanda efetiva dos serviços oferecidos em seu portfólio (Figura 2).

Ao final de 2002, a Alfa passa a operar o primeiro equipamento de RM, alavancando seu faturamento em valor e quantidade de exames. Por se tratar de exame de alta complexidade, o preço é muito superior ao dos demais do portfólio, passando a representar, até o final de 2004, 49\% do faturamento anual total em valores.

No primeiro ano, tanto a implantação dos protocolos como a realização dos laudos para os três níveis de complexidade (C1, C2 e C3) dos exames de RM foram efetuadas por um médico especialista contratado para tal. Uma das exigências da diretoria da empresa era a exclusividade do médico na prestação de serviço, principalmente se a capacitação do profissional era para exames de complexidade C2 e C3, o que caracterizava o vínculo empregatício do médico com a empresa.

Diante da forte demanda a cada ano e impulsionado pelo aumento expressivo do faturamento, o proprietário passou a investir intensivamente em novos equipamentos de RM e, ao final de 2006, toda a produção de laudos passou a ser distribuída a uma equipe de quatro a cinco radiologistas que se desenvolveram e se capacitaram pela técnica "aprender fazendo", por meio de aprendizado supervisionado, e cada um a seu tempo também buscou aperfeiçoamento em cursos e congressos da especialidade.

Os laudos dos exames com nível de complexidade C1 foram realizados por apenas um ou dois médicos da equipe e os outros, distribuídos aos demais da equipe.

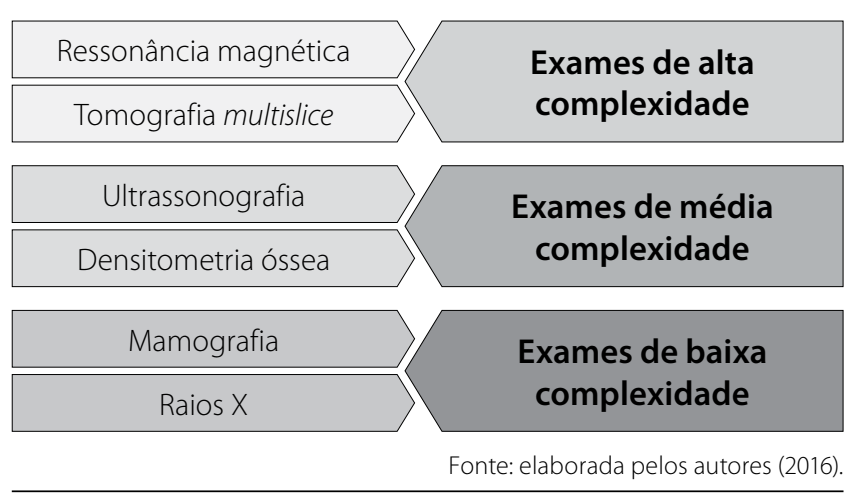

Figura 2. Portfólio da empresa Alfa.
O prazo de entrega dos laudos aos respectivos pacientes ocorria no terceiro dia após a realização dos exames de baixa e média complexidades, podendo chegar até cinco dias para os de alta. A Tabela 3 demonstra a demanda média diária por nível de complexidade.

O volume de laudos disponibilizados diariamente para a equipe de radiologia crescia diariamente e a rotina dos médicos não se restringia à execução do laudo, mas a atender às contingências que envolviam pacientes, preparos de exames, orientações à equipe técnica que opera os equipamentos, mas principal e prioritariamente aos médicos solicitantes dos exames. Os equipamentos operavam no limite da capacidade disponível e a atividade de laudo era desenvolvida internamente, portanto havia integração vertical, ou seja, hierarquia.

Em 2009, operando com três equipamentos de RM, o nível de crescimento do faturamento comparativamente aos anos anteriores reduziu na quantidade e mais significativamente em valores, demonstrando uma forte volatilidade da receita devido à evolução diferente para preços e volumes. Esse cenário apontava para tendência de estabilização da demanda.

A mão de obra médica para essa especialidade no mercado era escassa e a contratação e a retenção dos profissionais eram um grande desafio, pois a pressão por ganhos melhores não cedia.

De qualquer modo, para enfrentar essa ameaça, a Alfa decidiu adquirir toda a tecnologia para implantação de telerradiologia e armazenamento de imagens, e nos três anos iniciais a empresa utilizou apenas o recurso de armazenamento.

Com o desequilíbrio cada vez maior entre mão de obra médica disponível e o volume de laudos, apesar da resistência da equipe médica, a terceirização do serviço de laudo ocorreu na Alfa no início de 2012, pelo menos para os exames de baixa complexidade (C1). Assim, a estrutura de governança passou a ser híbrida (contrato bilateral).

A indisponibilidade de especialistas no mercado para dividir a demanda de alta complexidade era uma constante, mas sobravam médicos para exames de baixa complexidade (C1).

Tabela 3. Demonstrativa da demanda média diária por nível de complexidade

\begin{tabular}{lccc}
\hline $\begin{array}{l}\text { Nível de } \\
\text { complexidade }\end{array}$ & $\begin{array}{l}\text { Número de } \\
\text { médicos } \\
\text { disponíveis }\end{array}$ & $\begin{array}{l}\text { Quantidade de } \\
\text { exames/dia }\end{array}$ & $\begin{array}{l}\text { Prazo de } \\
\text { entrega do } \\
\text { laudo (dias) }\end{array}$ \\
\hline C1 & 5 & 50 & 3 \\
\hline C2 & 2 & 25 & 3 \\
\hline C3 & 2 & 5 & 5 \\
\hline Total & $5^{*}$ & 80 & \\
\hline
\end{tabular}

* Equipe composta de cinco radiologistas, considerando que o médico para os níveis C2 e C3 atende a C1, mas o contrário não ocorre. 
A equipe médica interna sempre resistiu à terceirização do serviço de laudo, pois tinha consciência de que estaria compartilhando e até transferindo competências desenvolvidas durante anos. A prontidão da equipe médica interna para esclarecimentos sobre achados clínicos aos colegas solicitantes sempre foi um diferencial, mas encontrava-se ameaçada agora pela terceirização, que impossibilitava o contato imediato, pois o médico assinante do laudo trabalha remotamente e o contato ocorreria em segunda instância.

As circunstâncias restringiam as alternativas e a equipe médica interna acabou optando pela terceirização dos laudos de complexidade $\mathrm{C}$, pois o risco de inconformidades seria menor. No início de 2012, assumiu os laudos C2 e C3.

Dessa forma, a estrutura de governança nessa transação que até 2011 era de integração vertical passou a ser um contrato bilateral (híbrida).

Em processo de crescimento, nenhuma empresa domina a totalidade dos conhecimentos necessários à realização do conjunto de atividades ao longo de sua cadeia produtiva. Todas elas devem, no mínimo, considerar a conveniência de especializar-se em algumas atividades e apoiar-se nas competências de outras empresas (Teixeira e Guerra, 2002).

A partir daquele ano, o diretor clínico instituiu a revisão de laudos e, semanalmente, por amostra aleatória, procedia a uma segunda leitura dos laudos da equipe médica terceirizada. Se houvesse qualquer inconformidade com o laudo padrão da Alfa, os prestadores eram advertidos e, na terceira reincidência, o médico prestador era substituído.

Paralelamente ao processo de evolução e crescimento das estruturas física e tecnológica, o proprietário decidiu como alternativa para fortalecer a marca e enfrentar essa realidade expandir o negócio com a abertura de uma nova unidade.

A Beta, também chamada de filial, foi inaugurada no início de 2012 como uma empresa de pequeno porte que ofereceria o mesmo portfólio de serviços da matriz em uma estrutura menor. Ao final de 2015, contava com 30 funcionários (técnicos, administrativos e de apoio), sendo quatro médicos, um deles radiologista.

Todos os equipamentos ociosos da matriz foram transferidos para a filial e um equipamento de RM da matriz oportunamente foi substituído por outro de última geração. Atualização da capacitação foi exigida das equipes médica e técnica, pois novos protocolos e procedimentos foram implantados, agora com mais complexidade.

No primeiro ano de funcionamento, os médicos radiologistas mais experientes da matriz revezavam-se diariamente na filial para implantar protocolos de exames de RM, causando um desfalque na Alfa, que enfrentava um forte crescimento de exames de alta e média complexidades (C2 e C3), por estar operando agora com um equipamento de ponta.
A manutenção da melhoria dos protocolos dos exames (imagens) e dos laudos sempre foi um diferencial perseguido. O padrão referenciado de laudo da corporação sempre foi desenvolvido e implementado pelo médico radiologista mais experiente com a equipe, que acumulava funções de executor de laudos e diretor clínico. Essa competência sempre ficou em desenvolvimento contínuo, pois, segundo o diretor clínico, exige persistência.

Um novo médico foi contratado para a Beta. As atividades de laudo foram, então, internalizadas, portanto ocorreu uma integração vertical, por meio de governança hierárquica. Os laudos desse médico eram submetidos à revisão conforme explicitado anteriormente.

Esse contexto mostra que aspectos internos à organização, como rotinas e competências, foram afetados pela estrutura de governança escolhida e vice-versa.

Após se constatar que a demanda da Beta não alavancou faturamento, o que de fato ocorreu foi uma transferência de demanda de Alfa. Os investimentos em soluções para telerradiologia que flexibilizariam a execução dos laudos a distância para essa unidade foram suspensos.

\section{Estruturas de governança}

A interação das características das transações (especificidades dos ativos, incerteza e frequência) com os pressupostos comportamentais (racionalidade limitada e oportunismo) pode indicar a estrutura de governança mais eficiente.

Neste estudo, as características das transações foram classificadas numa escala de níveis (baixo, médio e alto) e, posteriormente, as informações obtidas nas entrevistas com as empresas estudadas foram comparadas com o modelo de Brickely et al. (1997), citado por Zylbersztajn e Neves (2000) (Tabela 4), para verificar se as governanças observadas eram adequadas.

Tabela 4. Alinhamento dos contratos

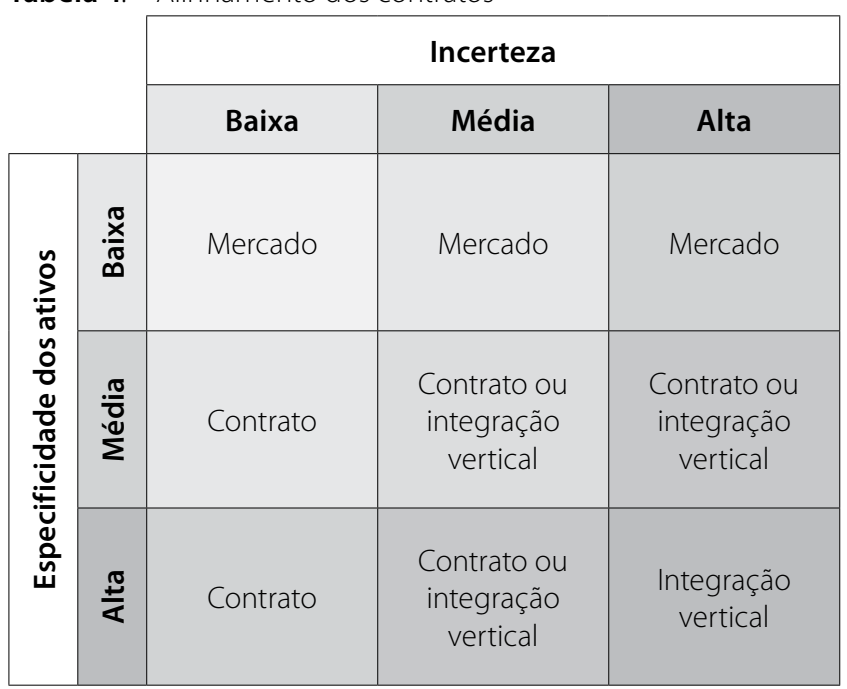

Fontes: Brickely et al. (1997); Zylbersztajn e Neves (2000). 


\section{Especificidade de ativos}

Para as duas empresas, o ativo específico é o humano, pois a atividade desenvolvida pelos profissionais requer conhecimento explícito e tácito, por isso a potencialidade da especificidade se define pela complexidade média ou alta do ativo (neste caso, o laudo) (Figura 1).

A especificidade dos ativos físicos e humanos encontrada para a corporação foi alta, pois o equipamento de acesso e transferência de imagens é a condição para acesso do laudo a distância e a atividade desenvolvida pelos profissionais requer conhecimento explícito, tácito e específico.

Tanto médicos como técnicos que operam os equipamentos de RM recebem treinamento no site para operar os equipamentos. Os médicos reconhecem o padrão dos protocolos dos exames e validam-nos, levando o tempo que for necessário e suficiente para um aprendizado satisfatório. Pode-se destacar como competência em desenvolvimento a capacitação da equipe médica reconhecida.

Os ativos dedicados têm especificidade média para Alfa e baixa para Beta, pois os recursos envolvidos têm dupla funcionalidade: acesso e transferência, como também armazenamento de imagens, então não tem exclusividade para as atividades de laudo. Assim, identifica-se como competência desenvolvida a tecnologia atualizada.

A locacional perde importância, já que a troca de dados é por transmissão. A Beta não dispõe desse recurso para acesso e arquivamento, sendo esse um dos motivos de internalização da atividade de laudo.

As informações quanto ao grau de especificidade por empresa constam na Tabela 5.

\section{Riscos e incertezas}

Por existirem muitas empresas que oferecem laudo a distância no mercado, a incerteza quanto à oferta é baixa para a corporação, o que se inverte quando o critério é qualidade, pois a corporação prioriza alta performance, qualidade acima da média e um laudo não só descritivo, mas conclusivo, sendo esse um dos diferenciais exigidos pelos médicos solicitantes e que define o grau máximo para Alfa, por realizar maior volume de exames de alta complexidade quando comparada a outras duas empresas. As competências em desenvolvimento apontadas são a confiança na precisão do laudo e a capacitação da equipe médica reconhecida.

Para os atributos riscos e incertezas, foram avaliadas a oferta e a qualidade do serviço prestado. Os resultados por empresa constam na Tabela 6.

\section{Frequência}

A Alfa tem frequência média-baixa e a necessidade de terceirização está relacionada à ausência de recursos internos em período de férias. A frequência é praticamente anulada
Tabela 5. Especificidades de ativos da corporação

\begin{tabular}{lll}
\hline Especificidade de ativos & Alfa & Beta \\
\hline Físico & Alta & Alta \\
\hline Humano & Alta & Alta \\
\hline Dedicados & Média & Baixa \\
\hline Locacional & Baixa & Baixa \\
\hline
\end{tabular}

Fonte: elaborada pelos autores conforme resultado da pesquisa (2016).

Tabela 6. Riscos e incertezas

\begin{tabular}{lll}
\hline Riscos e incertezas & Alfa & Beta \\
\hline Oferta & Baixa & Baixa \\
\hline Qualidade & Alta & Média \\
\hline
\end{tabular}

Fonte: elaborada pelos autores conforme resultado da pesquisa (2016).

na Beta em razão da especificidade alta de ativos, que a enquadra na estrutura de governança hierárquica. A frequência foi avaliada pelo volume de laudos enviados para a empresa contratada (Tabela 7). Os graus das três dimensões analisadas estão resumidos na Tabela 8.

O cruzamento das informações da Tabela 8 com a Tabela 4, conforme proposto pela metodologia, aponta para estruturas de governança mais adequadas nas transações de terceirização de laudos para cada empresa.

O formato de governança híbrida implicou terceirizar boa parte dos laudos, aliviando o risco de prorrogar o prazo de entrega dos laudos, um diferencial perante os concorrentes conquistado com muito esforço.

As formas de governança recomendadas na transação de terceirização dos serviços de laudo e a atualmente adotada em cada empresa analisada estão apontadas na Tabela 9.

\section{Competências organizacionais}

As competências identificadas nas pesquisas de satisfação dos níveis de serviço foram classificadas em categorias de

Tabela 7. Frequência

\begin{tabular}{lll}
\hline & Alfa & Beta \\
\hline Frequência & Média & Baixa \\
\hline
\end{tabular}

Fonte: elaborada pelos autores conforme resultado da pesquisa (2016).

Tabela 8. Resumo das dimensões dos custos de transação

\begin{tabular}{lll}
\hline Dimensões & Alfa & Beta \\
\hline Especificidades de ativos & Alta & Alta \\
\hline Riscos e Incertezas & Média & Média \\
\hline Frequência & Média & Baixa \\
\hline
\end{tabular}

Fonte: elaborada pelos autores conforme resultado da pesquisa (2016). 
Tabela 9. Formas de governança recomendadas x observadas nas empresas

\begin{tabular}{lll}
\hline Formas de governança & Alfa & Beta \\
\hline Mais adequada & $\begin{array}{l}\text { Contrato } \\
\text { (híbrida) }\end{array}$ & $\begin{array}{l}\text { Contrato bilateral } \\
\text { ou hierarquia }\end{array}$ \\
\hline Observada & Contrato bilateral & Hierarquia \\
\hline
\end{tabular}

Fonte: elaborado pelos autores conforme resultado da pesquisa (2016).

análise segundo as respectivas percepções: i) atendimento humanizado - foram consideradas as respostas que apontaram para limpeza do ambiente, conforto das instalações, receptividade, cordialidade nos atendimentos presencial e telefônico das atendentes; ii) tecnologia atualizada - consideraram-se as respostas quanto aos equipamentos médicos e computadores; iii) disponibilidade de conveniências - estacionamento com manobrista, entrega domiciliar dos resultados de exames, oferta de desjejum e acesso; iv) agilidade na entrega dos laudos: tempo reduzido entre a data de realização e a disponibilização do resultado; v) capacitação da equipe técnica (técnicos e médicos): reconhecimento da equipe interna e externamente; vi) confiabilidade nos laudos: padronização no formato do laudo (descrição e conclusão); acesso ao médico assinante do laudo para esclarecimento de dúvidas; vii) horário de funcionamento: funcionamento aos sábados e feriados

As competências essenciais apuradas estão apontadas na Tabela 10.

A distância das instalações físicas entre Alfa e Beta é de 30 $\mathrm{km}$, portanto atuam praticamente na mesma região. Dessa forma, as competências apuradas na pesquisa com os médicos solicitantes serão comuns a essas duas empresas, pois a fidelização deles ocorre com ambas. Essas competências apontadas na Tabela 11 se não essenciais, estão em desenvolvimento para tal. Estão relacionadas por ordem de importância definida pelos entrevistados.

Após apuração das competências que contribuíram para o valor percebido pelos principais clientes, as três melhores de cada perfil (de cliente) foram selecionadas como as potenciais competências a serem desenvolvidas e definidas como essenciais para as empresas: 1) atendimento humanizado; 2) agilidade na entrega dos laudos; 3) confiança na precisão do laudo; 4) capacitação da equipe médica reconhecida; 5) horário de funcionamento; 6) tecnologia atualizada.

Para verificar se tais competências atendem aos três critérios de competências essenciais, é preciso aplicar os conceitos conforme Prahalad e Hamel (1995), que são: i) aportar com uma contribuição importante ao valor percebido pelo cliente. Nesse critério, todas com diferentes intensidades representam a visão percebida pelos clientes; ii) contribuir para a expansão do negócio a médio e a longo prazo. Nesse critério, "confiança no médico solicitante" não depende do negócio, pois é um critério unilateral, ademais tem potencial para contribuir para o crescimento; iii) contribuir para a diferenciação da empresa com seus concorrentes e ser difícil de ser copiada. Todas podem ser copiadas, umas mais rápidas, outras menos. O desafio fica na constância de propósito da empresa para que se sustentem como diferenciais.

Dessas seis competências selecionadas, duas são potenciais contribuições para o desenvolvimento da verdadeira competência essencial: "confiança na precisão dos laudos" e "capacitação da equipe médica reconhecida".

As demais competências são consideradas competências organizacionais seletivas (Ruas et al., 2005), pois diferenciam a empresa dos concorrentes de acordo com os clientes, mas não atendem aos critérios totais de competência essencial. Sugere-se que a empresa continue com persistência a desenvolver essas seis principais competências organizacionais, e no caso das seletivas consideradas já desenvolvidas no ciclo de vida do negócio, que não as perca.

Para as duas competências organizacionais classificadas como essenciais, a empresa deve manter constância de propósito. No caso da competência que envolve confiança, sugerem-se a institucionalização dos protocolos de segunda leitura do laudo e a padronização de conteúdo não só descritivo (medidas e parâmetros da parte analisada), mas conclusivo (apontar e/ou sugerir a patologia relacionada com os achados nos laudos, dando sequência à investigação) também. Para a competência de capacitação, sugerem-se a ma-

Tabela 10. Competências essenciais na percepção dos clientes-pacientes

\begin{tabular}{lll}
\hline Público & Competências desenvolvidas por Alfa & $\%$ \\
\hline \multirow{3}{*}{$\begin{array}{l}\text { Cliente- } \\
\text { paciente }\end{array}$} & Atendimento humanizado & 5 \\
\cline { 2 - 3 } & Agilidade na entrega dos resultados & 9 \\
\cline { 2 - 3 } & Disponibilidade de conveniências & 8 \\
\cline { 2 - 3 } Hónário de funcionamento & 6 \\
\hline \multirow{3}{*}{$\begin{array}{l}\text { Cliente- } \\
\text { paciente }\end{array}$} & Competências desenvolvidas por Beta & $\%$ \\
\cline { 2 - 3 } & Atendimento humanizado & 6 \\
\cline { 2 - 3 } & Disponibilidade na entrega dos resultados de conveniências & 9 \\
\cline { 2 - 3 } & Horário de funcionamento & 8 \\
\hline
\end{tabular}

Fonte: elaborada pelos autores conforme resultado da pesquisa (2016).

Tabela 11. Competências essenciais na percepção dos clientes-médicos solicitantes

\begin{tabular}{|c|c|}
\hline Público & Competências desenvolvidas \\
\hline \multirow{4}{*}{$\begin{array}{l}\text { Cliente-médico } \\
\text { solicitante }\end{array}$} & Confiança na precisão do laudo \\
\hline & Capacitação da equipe médica \\
\hline & Tecnologia atualizada \\
\hline & Horário de funcionamento \\
\hline
\end{tabular}

Fonte: elaborada pelos autores conforme resultado da pesquisa (2016). 
nutenção de forma cada vez mais efetiva, a participação dos médicos em congressos, jornadas, cursos específicos e apresentação de estudos de caso em grupos de estudos reconhecidos; exigência de certificações de especialista na área.

\section{Resultados}

este estudo tentou estabelecer com certo esforço as relações entre as abordagens da ECT e competências organizacionais, analisando a influência da estrutura de governança escolhida, no desenvolvimento de competências organizacionais em duas empresas do setor de saúde.

A estrutura de governança escolhida durante muitos anos pela corporação foi a hierarquia, cujo foco estava na atividade-fim da empresa. Durante o período dessa governança, muitas competências se desenvolveram, estabeleceram-se, fortaleceram-se, embora algumas possam até ter sido abandonadas.

\section{Conclusão}

Os estudos de Porter (1999) confirmam que "é difícil desempenhar todas as atividades com a mesma produtividade dos especialistas". Tanto que a opção pela terceirização teve o reconhecimento crescente de que é difícil ser competente em tudo.

Quando a estrutura de governança da matriz passou a ser híbrida, de certa forma a empresa expôs suas necessidades, deficiências e competências ao mercado. Esse ponto foi muito explorado pelo proprietário na entrevista.

Internamente, conflitos de interesse se manifestaram, principalmente com os funcionários diretamente ligados às tarefas parcialmente terceirizadas no caso em estudo. Pode-se citar alguns: a) posturas individualistas de ambas as partes (o esforço para entrega de valor ao cliente diminui; as responsabilidades precisam ser claramente estabelecidas, se não fica "deixa que eu deixo"); b) valorização das competências individuais do funcionário quando o terceirizado não cumpre algo no contrato; c) desconstrução de competências (os laudos terceirizados contribuem para afastar o cliente médico fidelizado).

O estudo demonstrou que as estruturas de governança podem não só influenciar, mas também interagir com o desenvolvimento das competências organizacionais.

O estudo contribuiu para o entendimento do impasse pelo qual as empresas de serviço do ramo de diagnóstico vêm passando, que é a falta de disposição e interesse dos profissionais médicos em se manterem exclusivos a elas, principalmente se estas forem de pequeno e médio portes.
Radiologistas não interagem muito com o paciente, talvez sendo esse um fator contributivo e fortalecedor pelo interesse do trabalho a distância. Tal fato está na contramão da estratégia de empresas orientadas a serviços que reconhecem como uma das suas principais e importantes características estar próximas ao cliente.

Esse tem sido o maior desafio para os tomadores desse serviço que, muitas vezes pressionados pela falta de profissionais, acabam recorrendo a essa modalidade, terceirizando atividades importantes, sob o risco de terceirizar também competências que demoraram muito a ser desenvolvidas. Como administrar custos ocultos como esse? A realização de mais estudos e pesquisas contribuiria para aprofundar o conhecimento desse assunto.

\section{Referências bibliográficas}

Coase RH. The nature of the firm. Econômica. 1937;4:386-405.

Fiani R. Teoria dos custos de transação. In: Kupfer D, Hasenclever L. Economia industrial - Fundamentos teóricos e práticos no Brasil. Rio de Janeiro: Campus, 2002.

Fleury A, Fleury MT. Estratégias empresariais e formação de competências: um quebra-cabeça caleidoscópio da indústria brasileira. São Paulo: Atlas, 2010.

Gil AC. Como elaborar projetos de pesquisa. 5. ed. São Paulo: Atlas, 2010.

King EA. Competências organizacionais e vantagem competitiva: o desafio da gerência intermediária. RAE - Revista de Administração de Empresas. 2002:42:36-49.

Pondé JL. Coordenação, custos de transação e inovações institucionais. Texto para Discussão, IE/Unicamp, Campinas, n. 38, 1994.

Porter ME. Competição: estratégias competitivas essenciais. 8. ed. Rio de Janeiro: Campus, 1999.

Prahalad CK, Hamel G. Competindo pelo futuro: estratégias inovadoras para obter o controle do seu setor e criar os mercados de amanhã. Rio de Janeiro: Campus, 1995.

Ruas RL, Antonello CS, Boff LH (orgs.). Os novos horizontes da gestão: aprendizagem organizacional e competências. Porto Alegre: Bookman, 2005.

Teixeira F, Guerra O. Redes de aprendizado em sistemas complexos de produção. ERA - Revista de Administração de Empresas. 2002;42:93-105.

Williamson OE. Transaction-cost economics: the governance of contractual relations. The Journal of Law \& Economics. 1979;22(2):233-61. Disponível em: http://dx.doi. org/10.1086/466942. Acesso em: 13 ago 2018.

Williamson OE. The economic institutions of capitalism: firms, markets, relational contracting. New York: The Free Press, 1985.

Williamson OE. Comparative economic organization: the analysis of discrete structural alternatives. Administrative Science Quarterly. 1991;36(2):269-96.

Williamson OE. Transaction cost economic and organization theory. Journal of Industrial Corporate Change. 1993;2(2):107-56.

Yin RK. Estudo de caso: planejamento e métodos. Porto Alegre: Bookman, 2001.

Zybersztajn D, Neves MF (orgs.). Economia e gestão dos negócios agroalimentares. São Paulo: Pioneira, 2000. 